\title{
Repensar la publicidad local en tiempos de crisis
}

Radiografía de la publicidad en la prensa alicantina: estrategias para tiempos de crisis

Alicia DE LARA GONZÁLEZ

Alicante: Publicaciones Instituto Alicantino de Cultural Juan Gil Albert (colección Comunicación), 2013.

155 páginas.

ISBN: 978-84-7784-649-9.

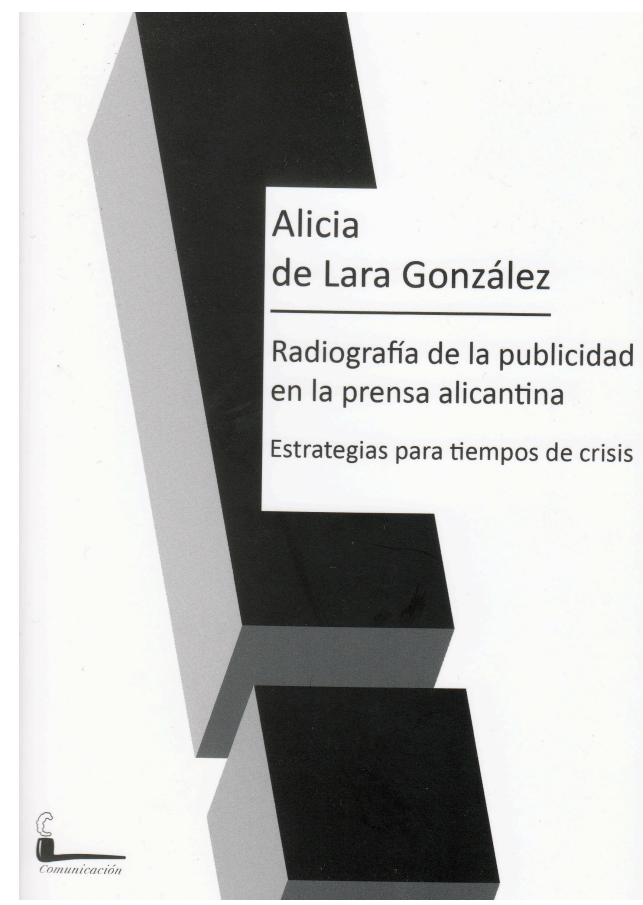

\section{Dr. José Luis GONZÁLEZ ESTEBAN*}

Vicedecano de la Titulación de Periodismo. Profesor Titular. UMH. España. jose.gonzalez@umh.es

\section{La encrucijada de la prensa local regional a través del prisma publicitario}

Durante los últimos años se han realizado numerosos estudios analizando la crisis de la prensa tradicional en España y aportando claves, más o menos acertadas, para su necesaria reinvención. La crisis global, unida a una crisis del sector prensa, ha golpeado duramente a uno de los eslabones más débiles, pero a la vez más necesarios: el periodismo de proximidad. Tal es así que en el ecosistema mediático local que analiza este libro se han producido cambios traumáticos en muy poco tiempo. En este sentido, cabe destacar el caso de uno de los medios investigados por la autora: el diario La Verdad. Cuando se inicia esta investigación, Vocento, empresa propietaria de La Verdad de Murcia, todavía mantenía las ediciones de Albacete y Elche (fundadas en los años setenta del pasado siglo) y Alicante. A día de hoy, la única edición que ha sobrevivido a la crisis es la de Alicante que por otra parte es uno de los objetos de estudio 
de este libro, junto con el diario Información, líder en esta provincia y propiedad del grupo Prensa lbérica.

La novedad e interés de este libro editado por el Instituto Alicantino de Cultura Juan Gil Albert, en su colección de Comunicación, es abordar el asunto a partir del prisma publicitario, mostrando una veraz radiografía de la publicidad en la prensa alicantina como síntoma de la problemática del sector. Pero el libro no se queda en un concienzudo análisis de contenido para mostrar esa fotografía nítida de la publicidad en la prensa local de este territorio, se da un paso más y se plantean estrategias para revertir la situación en la medida de lo posible.

Nos encontramos, por tanto, con un libro fruto de una profunda investigación que dio lugar a una tesis doctoral y que avanza soluciones de futuro. Se plantean interrogantes y respuestas bien elaboradas que resultan de suma utilidad.

La obra se estructura en seis partes, iniciándose con una introducción, una aproximación al objeto de estudio, profundizándose en el papel de la publicidad en la supervivencia del periódico local. En este sentido, en la segunda parte, la autora desarrolla perspectivas críticas en referencia al uso de la publicidad en el formato clásico del papel en los medios locales comentados, y explica la relación entre el contenido publicitario y el editorial, además de hacer un análisis detallado de las principales características de la publicidad local: estacionalidad y secciones, formatos y paginación, ámbito geográfico, sectores de inversión y coherencia geográfica y temática. Además, explica particularidades de esta tipología local como la evolución de la publicidad de recurso o la involución de la publicidad de esquelas y necrológicas, en otros tiempos importe sustento económico de los periódicos locales.

Una vez planteado todo este marco teórico relacionado con el producto clásico, es decir, el formato papel, la autora se introduce en la controvertida publicidad online, controvertida por el poco rendimiento económico que éstos y otros medios tradicionales le han sacado hasta la fecha. En el libro se puede encontrar un pequeño recorrido histórico sobre la transición publicitaria en estos medios locales: del módulo al clic, aportándose soluciones para rentabilizar el medio digital y analizando las fortalezas y debilidades que en este sentido tienen las ediciones online de los diarios Información y La Verdad. De igual forma se hace una comparativa entre las versiones impresas y digitales de ambos periódicos y sobre los principales inversores publicitarios.

Con el objeto de estudio muy bien centrado, los capítulos cuarto y quinto se proponen para ofrecer soluciones a interrogantes que tienen ver con la hibridación de contenidos, cuestiones legales y deontológicas, la tipología de los publirreportajes, la promoción de productos o la importancia y trato que se le da a la autorreferencia, tanto en las versiones print como online. Algunos de los interrogantes que se plantean y responden con acierto son: żpuede un medio tradicional como el diario impreso albergar publicidad no convencionale, ¿̇de qué tipo de publicidad no convencional estamos hablando?, ¿̇resulta lícito hibridar contenidos publicitarios y editoriales? o ¿̇cómo se lleva a cabo esta hibridación y en qué medida afecta al resultado final del ejemplar? En cuanto a la autorreferencia o cuando los diarios hablan de sí mismos, los tres interrogantes que dan lugar al desarrollo de propuestas concretas son: ¿̇a qué nos referimos cuando abordamos la autorreferencia en el diario impreso?, ¿̇se utilizan los contenidos publicitarios propios de acuerdo a una estrategia y objetivos definidos? y ison coherentes los frutos que se pretenden obtener de la estrategia de promoción de ventas?

Todas estas preguntas obtienen respuestas que finalmente se concretizan en una clasificación y su análisis DAFO correspondiente que viene a sintetizar este riguroso y pormenorizado estudio sobre la evolución e importancia de la publicidad en la prensa alicantina en un momento clave para este sector. 